\title{
Deep Structure of the Lithosphere in the Central Tien Shan along the Son-Kul Magnetotelluric Sounding Profile
}

\author{
A. K. Rybin ${ }^{a, *}$, E. A. Bataleva ${ }^{a}$, V. E. Matiukov ${ }^{a}$, \\ Corresponding Member of the RAS Yu. A. Morozov ${ }^{b}$, and K. S. Nepeina ${ }^{a}$ \\ Received October 20, 2020; revised November 16, 2020; accepted November 17, 2020
}

\begin{abstract}
New results of a detailed study of the deep structure of the Central Tien Shan along the Son-Kul magnetotelluric (MT) profile crossing the Son-Kul Lake are reported. Based on the results of magnetotelluric data modeling, the regional and local geoelectric anomalies in the lithosphere are studied and their quantitative characteristics are given. Geological interpretation of the geoelectric cross-section was carried out, which supported the existing ideas about the block-hierarchical structure of the upper part of the Earth's crust. This corresponds to the tectonophysical concepts of the sequential inserted subordination of large and smaller elements of the zone-block structure consisting of stable blocks and limiting mobile zones, which are distinguished by the high dislocation of the geological substrate. The integral pattern of the distribution and morphology of zones of high electrical conductivity in this segment of the Central Tien Shan crust may reflect discretely localized palm tree-type structures associated with the evolution of transgressive suture zones of localized deformation during the Hercynian and Alpine tectogenesis.
\end{abstract}

Keywords: magnetotelluric sounding, electrical conductivity, geoelectric model, deep structure, Central Tien Shan

DOI: $10.1134 / \mathrm{S} 1028334 \mathrm{X} 21020161$

\section{INTRODUCTION}

The study of the distribution of deep structuralmaterial heterogeneities, as well as their complex geological and geophysical characterization, is one of the most important problems of modern tectonics and geodynamics. The fact that magnetotelluric sounding (MTS) is most sensitive to conductive structures in the Earth's crust and upper mantle, most likely due to the presence of fluids, makes it one of the most successful deep geophysical methods in the study of fault structures in geodynamically active regions [1-3]. The Son-Kul Basin is a flat area with dimensions of $\sim 29 \times$ $57 \mathrm{~km}$ (Son-Kul Lake has a size of $19 \times 25 \mathrm{~km}$ ), its shape is close to an ellipse elongated in the latitudinal direction. It is located at an altitude of just over $3000 \mathrm{~m}$ and separated by ridges, the crests of which are raised to $3800 \mathrm{~m}$ and more. These ridges are the part of the Moldotau-Terskey system of uplifts. Geographically, the Son-Kul Basin is a link in an extremely extended zone of highly elevated and relatively narrow (valleylike) intermontane basins [4]. In the west, it is sepa-

\footnotetext{
${ }^{a}$ Research Station of the Russian Academy of Sciences, Bishkek, Kyrgyzstan

${ }^{b}$ Schmidt Institute of the Physics of the Earth, Russian Academy of Sciences, Moscow, 123995 Russia

*e-mail: rybin@gdirc.ru
}

rated by sublatitudinal faults and linear grabens of the Minkush-Kokomeren Zone; in the east, the OttukKokturpak and further Archalu-Dzhinalach basins are observed in the relief (Fig. 1). Noteworthy is the anomalously large width of the Son-Kul Basin $(\sim 20 \mathrm{~km})$, which gives it an almost isometric outline. This isometric shape, which sharply distinguishes the SonKul Basin from the grabens of the MinkushKokomeren Zone, is controlled by the absence of large faults on the sides of the basin, as well as by the younger age of the Son-Kul Basin, overprinted on the more ancient troughs of the Minkush-Kokomeren Zone. There are no Jurassic and Oligocene-Neogene sediments (Kyrgyz and Naryn formations) within the Son-Kul Basin, and only low-thickness Quaternary sediments occur there. Structurally and historically, the Son-Kul Basin is not an element of the MinkushKokomeren Zone of linear grabens; it is the younger overprinted basin. It was previously believed that a vast and deep granitoid batholith was the base of the basin. However, in light of later reconstructions, the Son$\mathrm{Kul}$ granitoid massif is not considered as a batholith any longer, but is a rather thin plate, which almost does not differ from the host formations in its rheological properties. The influence of deep tectonic dislocations of the regional order in this area was considered as a likely reason for the presence of a large granitoid massif with anomalous values of apparent resistivity as 


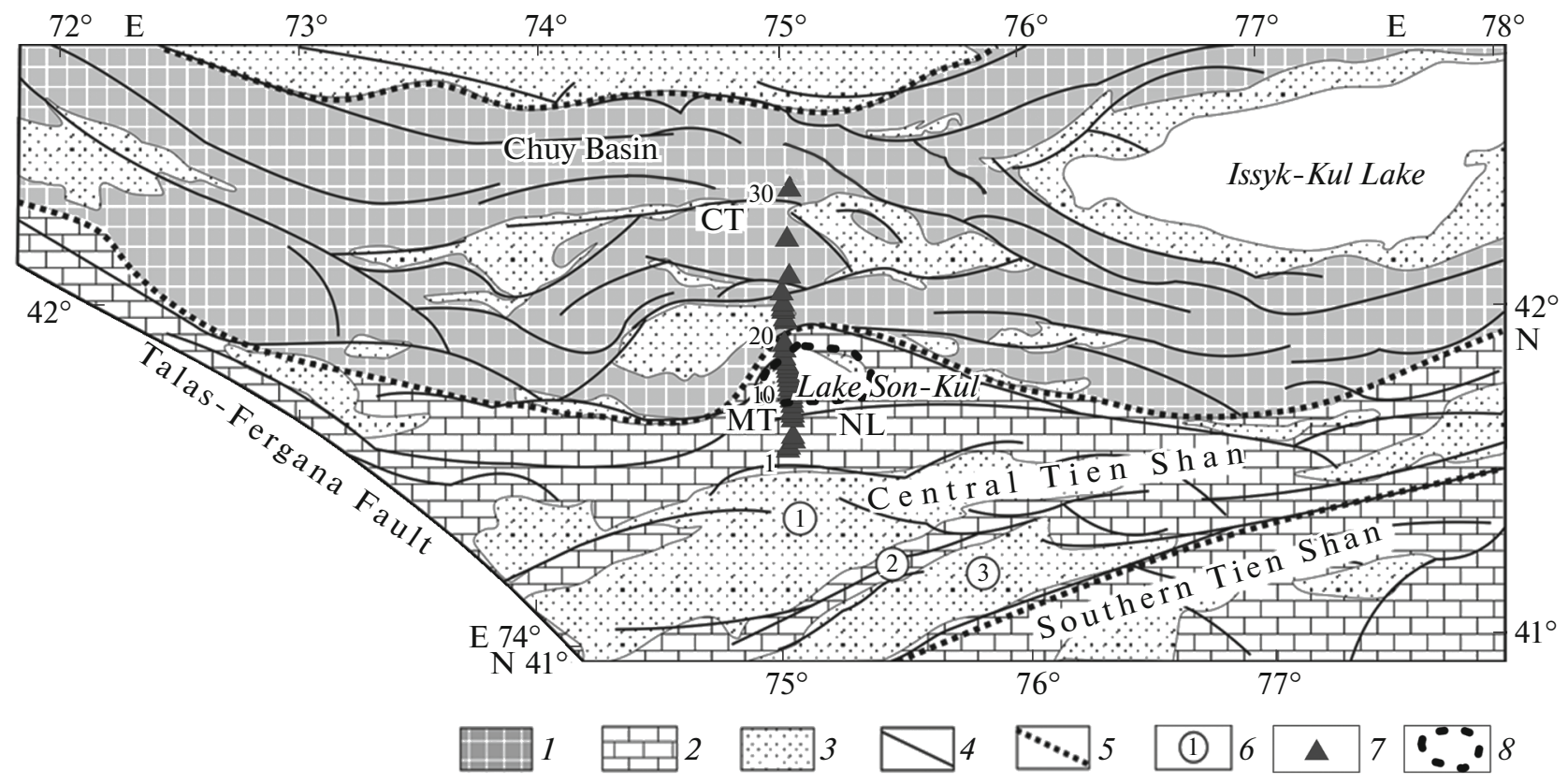

Fig. 1. Schematic geological map of the Central Tien Shan with the Son-Kul magnetotelluric sounding profile, crossing the Moldo-Too Uplift (MT), Nikolaev Line (NL), and the Central Terskey fault (CT) in the meridional direction. (1) Caledonian basement of the Northern Tien Shan; (2) Hercynian basement of the Central and Southern Tien Shan; (3) depressions filled with Meso-Cenozoic deposits; (4) main faults; (5) main tectonic faults: Atbashi-Inylchek and Nikolaev Line; (6) elements of the system 1-Naryn Basin, 2-Baibichetoo Uplift, 3-Atbashi Basin; (7) MTS points of the Son-Kul profile; (8) boundaries of the Son-Kul Basin.

well $[3,5]$. The magnetotelluric sounding performed in this study can provide the prerequisites for clarifying the answer to the following question: are the geoelectric anomalies discovered associated with deep tectonic faults or with fracturing of the Son-Kul granitoid massif itself. The most important tectonic structure of the Central Tien Shan, known as the Nikolaev Line, stretches in the immediate vicinity. It is very important in many structural, paleotectonic, geophysical, and other reconstructions, being considered as one of the fundamental deep-seated elements of the Tien Shan structure. At the same time, this largest structural boundary between the uneven-aged formations of the Northern and Central Tien Shan practically does not manifest itself in the neotectonic structure, while being well reflected in the results of deep electromagnetic studies. Another structural element that may appear in the geoelectric model is the so-called Kyrgyz-Terskey oceanic suture zone [6], which is observed from the western part of the Kyrgyz Range to the southeast, to the area of Lake Son-Kul and then to the east, to the upper reaches of the Naryn River. On the other hand, the deep structure of the studied region as a part of the Issyk-Kul microcontinent is of particular interest to many scientists as well [7-9]. It may be expected that the detailed magnetotelluric sounding performed will provide more definite data for the solution of these problems, which are of not only regional, but general scientific interest as well. Therefore, the MTS study was carried out along the
Son-Kul profile, which was laid across the strike of the major tectonic structures of the Central Tien Shan on the territory of the Son-Kul Basin, by the Research Station of the Russian Academy of Sciences in Bishkek, with the support of the Russian Science Foundation, project no. 17-16-10059 (Fig. 1).

\section{METHODS OF STUDY}

Our work was aimed at study of the deep geoelectric structure and its comparison with the geological structure in order to substantiate the structure of the lithosphere along the Son-Kul MTS profile. For this purpose, new detailed MTS was performed along a profile parallel to the 75th meridian (Fig. 1) and crossing the major tectonic elements of the Northern Tien Shan: the Kyrgyz, Dzhumgal-Too, Son-Kul-Too, and Moldo-Too ranges, Son-Kul Basin, fault zones of different ranks, and the ophiolite zone confined to SonKul Lake. The total length of the profile was $90 \mathrm{~km}$, and it included 30 sounding points. The study along the profile was carried out with different steps (from 1 to $15 \mathrm{~km}$ ), depending on the field conditions. We used a Phoenix MTU-5A equipment in the range of periods from 0.001 to $1600 \mathrm{~s}$. The measurements of the three components of the magnetic field were carried out using standard MTC-50 induction coils oriented to the north, east, and vertically. The components of the electric field were measured by dipoles with a length of $50 \mathrm{~m}$, grounded by nonpolarizable electrodes with 

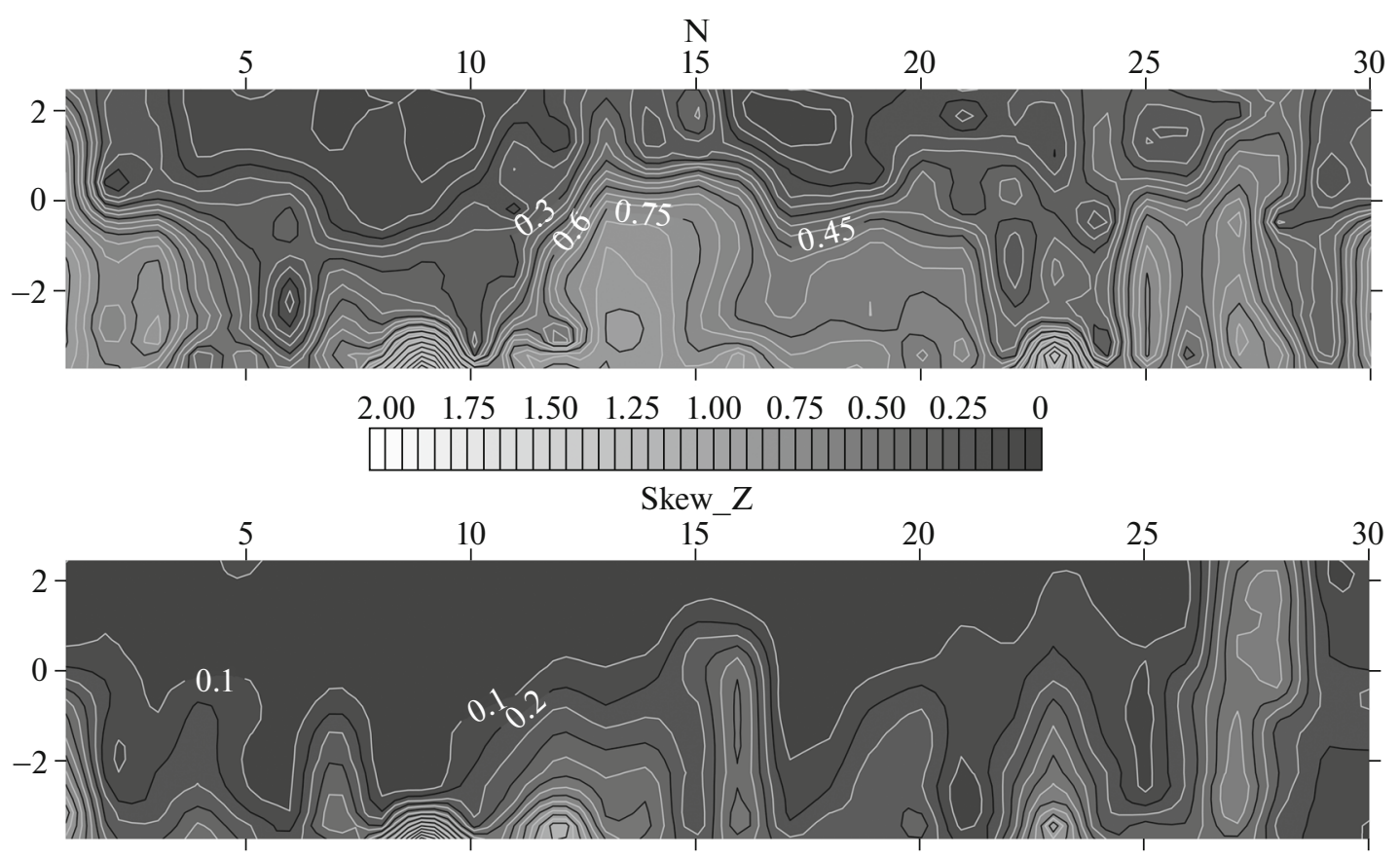

$\begin{array}{lllllllllllll}2.2 & 2.0 & 1.8 & 1.6 & 1.4 & 1.2 & 1.0 & 0.8 & 0.6 & 0.4 & 0.2 & 0\end{array}$

Fig. 2. Pseudo-sections of magnetotelluric parameters $N$ and skew.

manganese-carbon powder, designed and patented by the Research Station of the Russian Academy of Sciences. The data processing was performed in the onepoint mode only. Mathematical processing of the data of field soundings obtained along the Son-Kul profile was carried out using the standard software package SSMT-2000 (Phoenix). As a result, the frequency dependences of the components of the impedance tensor and the Wiese-Parkinson matrix were obtained in the range of periods from 0.001 to $1600 \mathrm{~s}$.

Based on the results of MTS data processing, estimates of the impedance tensor, tippers, and horizontal magnetic tensor were obtained using the MT-Corrector software (worked out by the Nord-West Company, Russia), according to the standard research scheme for the Tien Shan region [10-13].

\section{RESULTS OF THE STUDY AND ANALYSIS}

The qualitative and quantitative interpretation of the data obtained was carried out by the methodology considered in [10-13]. The construction of the geoelectric model along the Son-Kul profile included the parameterization of the impedance, i.e., the determination of the inhomogeneity parameters $N$ and the amplitude parameter of asymmetry Skew (Fig. 2). These constructions are necessary for regionalization of the area studied by to the "electrical dimension" of the environment and allow us to assess the degree of horizontal heterogeneity of the environment and localize the structures identified.

The inhomogeneity parameter $N$ is determined by the formula

$$
N=\left|\frac{Z_{p}^{+}-Z_{p}^{-}}{Z_{p}^{+}-Z_{p}^{-}}\right|,
$$

where $Z_{p}^{+}$and $Z_{p}^{-}$are the principal values of the impedance tensor determined by the Eggers orthogonalization method [14]. It characterizes the degree of horizontal heterogeneity of the environment. If the environment is horizontally homogeneous (1D), then $N=0$.

The amplitude parameter of asymmetry [14] skew is a measure of the asymmetry of the environment as well. In the case of a two-dimensional model, skew $=0$.

$$
\text { skew }=\left|\frac{Z_{x x}+Z_{y y}}{Z_{x y}-Z_{y x}}\right| .
$$

The pseudo-sections skew and $N$ characterize the degree of horizontal inhomogeneity of the environment; the skew value is 0.1 up to significant depths, which indicates the probability of using 2D inversion of MTS data. This is evident from the pseudo-section of the parameter $N$; this parameter does not have anomalous behavior (as is often the case). 


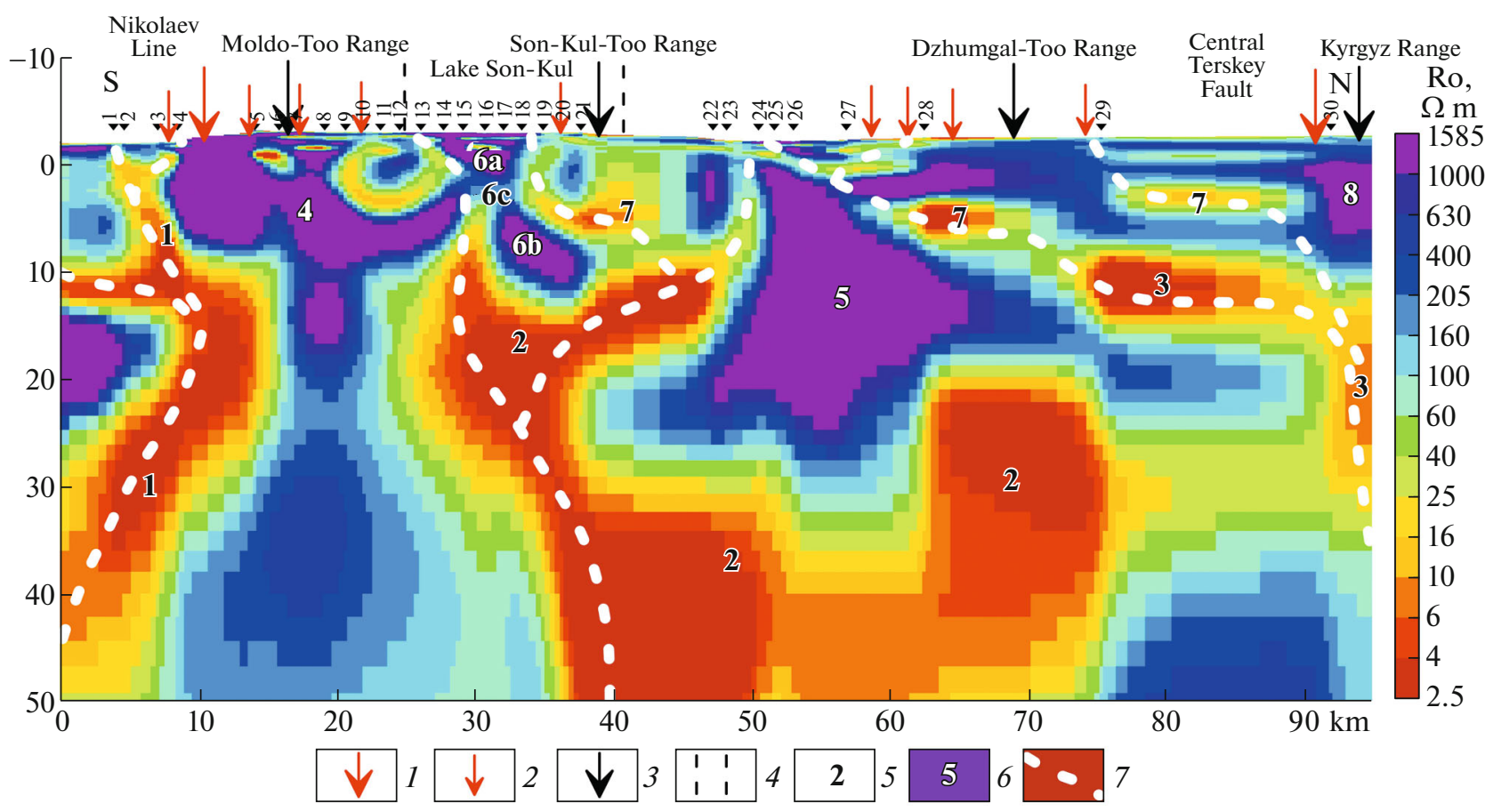

Fig. 3. Deep geoelectric model along the Son-Kul MTS profile. Faults: (1) major tectonic: Nikolaev Line and Central Terskey, (2) minor; (3) ranges; (4) boundaries of Son-Kul Lake; the numbers indicate the structures (see description in the text): (5) conducting, (6) high resistivity; (7) zones of localization of tectonic deformations that characterize the style of transpressive structures of the palm tree-type.

A two-dimensional smoothing inversion of MTS data along the Son-Kul profile (Fig. 3) was performed using the Rodi-Mackie software [15].

This program uses a nonlinear conjugate gradient method that attempts to minimize the objective function, which is the total of the normalized data residuals and model smoothness. The relationship between data discrepancies and model smoothness is controlled by the regularization parameter $\tau$. The input data for the inversion are the longitudinal and transverse curves of the apparent resistivity and impedance phases (TEand TM-modes in the designations of this program), and tippers at 30 observation points in the period range from 0.01 to $1000 \mathrm{~s}$. The mesh of the approximation model consists of 179 cells horizontally, sparse at the edges of the model and more frequent near sounding points, and 151 cells vertically, increasing in size with depth. The terrain relief is taken into account for detailed construction of the mesh (with a step of $50 \mathrm{~m}$ ). The resistivity of the starting model is $100 \Omega \mathrm{m}$. The error limits of the inverted data were set as follows: apparent resistivity modulus (TE mode), 100\%; apparent resistivity modulus (TM mode), 10\%; impedance phase (TE mode), 5\%; impedance phase (TM mode), 5\%; tipper, $0.05 \%$. Based on several test calculations of the inversion, the value of the regularization parameter $\tau=3$ was selected. The model shown in Fig. 3 was obtained after 200 iterations. The value of the RMS residual (inversion convergence) was 2.54.

\section{GEOLOGICAL INTERPRETATION OF THE GEOELECTRIC SECTION}

The resulting geoelectric model is shown in Fig. 3, where the key heterogeneities of the cross-section are numbered for easier interpretation and the numbers in the text are indicated by numerals in parentheses. In general, the model is characterized by a contrasting distribution of objects with different resistivity. For the upper part of the cross-section, there is a good correlation between the high-resistivity blocks of the model and mountain ranges, such as Moldo-Too (4), Dzhumgal-Too, and Kyrgyz (8), with the exception of the Son-Kul-Too Range. The Nikolaev Line Zone (1) is the most contrasting subvertical geoelectric structure, which is characterized by an anomalously low resistivity $(2-10 \Omega \mathrm{m})$ with a depth of $45-50 \mathrm{~km}$, and it is the border between the Northern and Central Tien Shan. The maximum width of the anomalous zone of high electrical conductivity reaches $5-7 \mathrm{~km}$. The physical nature of the high conductivity can be associated both with the general fluid saturation of adjacent faults and with the syn-deformational processes of illitization of clays and hydration of feldspars in the clays of friction over Jurassic rocks in the neighboring 
Minkush-Kokomeren suture zone detected in the upper part of the section [16].

The high-resistivity block (5) forming the central part of the cross-section may be composed of felsic igneous rocks (?) and is the axial part of the Issyk-Kul microcontinent $[7,8,17]$. Based on the results of observations of rock outcrops, the conducting horseshoe-shaped structure surrounding the high-resistivity block (2) is most likely composed of Precambrian mica-bearing granite-gneiss and metamorphic rocks, which are characterized by intense fracturing and, as a result, high fluid saturation. Such rocks compose the lower part of the Issyk-Kul microcontinent, the boundary of which passes into the lower crustal conductive layer. In addition, the Central Terskey fault zone appears in the geoelectric section near the area of point 30 (Fig. 3). The mosaic distribution of areas (objects) with high electrical conductivity (points 29 and 30) in the conjunction zone of the Kyrgyz Range and the Dzhumgal Basin may be explained by the fragmentary structure of the deep fault consisting of a number of separate backstage faults with a length up to $15 \mathrm{~km}$. The zone of the high gradient of electrical resistivity at sounding points 22 and 23 on the geoelectric cross-section corresponds to the ophiolite suture [6], which includes fragments of the ancient oceanic crust.

Noteworthy are the two high-resistivity bodies located directly beneath Son-Kul Lake (6a) and at depths of 6-12 km (6b), with the values of apparent resistivity (AR) $1000-1600 \Omega \mathrm{m}$ and separated by a horizontal electrically conductive zone $(\mathrm{AR}=160-$ $200 \Omega \mathrm{m}$ ) at a depth of $\sim 5 \mathrm{~km}(6 \mathrm{c})$, which may be due to intense fracturing of rocks. The high-resistivity objects (6a) and (6b) may have previously composed a single body, a large intrusive massif comparable in size to a batholith, the depth of which reaches $15 \mathrm{~km}$ and the thickness of which is $\sim 6 \mathrm{~km}$.

The subhorizontal zone of high electrical conductivity (7) may be due to tectonic disintegration of rocks and their high fluid saturation; this is in a good agreement with the position of the upper crustal conductive layer, sporadically distributed throughout the entire Central Tien Shan [18].

In general, the integral pattern of the distribution and morphology of zones of high electrical conductivity in this crustal segment of the Central and Northern Tien Shan may reflect, in our opinion, a discretely localized manifestation of palm tree-type structures associated with the evolution of transpressive suture zones of local deformation during the Hercynian and Alpine tectogenesis [19]. As a rule, the latter are combined with compensatory structures of transtension in the form of pull-apart intermontane basins spatially and hierarchically $[5,20]$.

\section{CONCLUSIONS}

Thus, a comparative analysis of geological and geophysical data on key elements of the geoelectric model developed along the Son-Kul MTS profile was carried out. Due to the significantly more detailed and accurate MTS data, the boundaries of the Issyk-Kul microcontinent corresponding to modern tectonic concepts were obtained in the conductive structures of the constructed geoelectric cross-section at the stage of qualitative interpretation and the first quantitative estimates. The fault zones are clearly identified in the geoelectric cross-section in the form of subvertical conductive heterogeneities with different slopes of the interpreted deep structures. According to the currently available geological and geophysical data (the results of study on earthquake sources, the results of GPS measurements, structural-geological studies) for the Central Tien Shan, the zone considered occurs under the conditions of general horizontal submeridional compression. Thrust faults formed in horizontal compression settings can subside both northward and southward. This conclusion is supported by the crosssection constructed. Most likely, geoelectric anomalies (highly conductive structures) have different vergence and shape, similar to those of palm tree-type transpressive suture structures. The distribution of high-resistivity objects in the upper part of the crosssection (to depths of $\sim 25 \mathrm{~km}$ ) supports the existing ideas about the block-hierarchical structure of the upper part of the Earth's crust in the Central Tien Shan, and the size of the blocks reflects the degree of discreteness of its tectonic processing. Such representation for the upper part of the Earth's crust is in agreement with the tectonophysical concepts of a system of successively enclosed smaller elements in larger stable ones (a zone-block structure), as well as the presence of mobile zones limiting them. It is accepted that such mobile zones differ from stable blocks by the high dislocation of the geological substrate.

\section{FUNDING}

This study was supported by the Russian Science Foundation, project no. 16-17-10059 (field magnetotelluric sounding, processing, and analysis of MTS field records, construction of an interpretive geoelectric model) and was performed as a part of a State Assignment of the Institute of the Physics of the Earth, Russian Academy of Sciences, project no. 0144-2014-0089 (collection of a priori geological and tectonic information, geological interpretation of the geoelectric structure).

\section{OPEN ACCESS}

This article is distributed under the terms of the Creative Commons Attribution 4.0 International Public License (http://creativecommons.org/licenses/by/4.0/), which permits unrestricted use, distribution, and reproduction in any medium provided you give appropriate credit to the original 
author(s) and the source, provide a link to the Creative Commons license, and indicate if changes were made.

\section{REFERENCES}

1. A. K. Rybin, V. Yu. Batalev, P. V. Il'ichev, and G. G. Shchelochkov, Russ. Geol. Geophys. 42 (10), 1566-1573 (2001).

2. E. A. Bataleva, M. M. Buslov, A. K. Rybin, V. Yu. Batalev, and I. V. Safronov, Russ. Geol. Geophys. 47 (9), 1023-1029 (2006).

3. V. I. Makarov, D. V. Alekseev, M. G. Leonov, V. Y. Batalev, E. A. Bataleva, V. D. Bragin, A. K. Rybin, G. G. Shchelochkov, I. V. Belyaev, N. T. Dergunov, N. N. Efimova, Y. V. Roslov, L. M. Munirova, A. D. Pavlenkin, and S. Roecker, Geotectonics 44 (2), 102-126 (2010). https://doi.org/10.1134/S0016852110020020

4. V. I. Makarov, The Newest Tectonic Structure of Tenshu (Moscow, 1977) [in Russian].

5. Yu. A. Morozov, M. G. Leonov, and D. V. Alekseev, Geotectonics 48 (1), 24-54 (2014).

6. M. G. Lomize, L. I. Demina, and A. A. Zarshchikov, Geotectonics 31 (6), 463-483 (1997).

7. V. Yu. Batalev, E. A. Bataleva, V. V. Egorova, V. E. Matyukov, and A. K. Rybin, Russ. Geol. Geophys. 52 (12), 1592-1599 (2011).

8. E. A. Bataleva and V. Yu. Batalev, in Proc. 44th Tecton. Meet. "Tectonics of Eurasian Fold Belts: Similarities, Characteristic Features of Recent Orogeny, and Regional Generalization” (GEOS, Moscow, 2014), Vol. 1, pp. 913 [in Russian].

9. M. M. Buslov, J. De Grave, E. A. Bataleva, and V. Yu. Batalev, J. Asian Earth Sci. 29, 205-214 (2007).

10. A. K. Rybin, E. A. Bataleva, V. Y. Batalev, V. E. Matyukov, O. B. Zabinyakova, V. O. Nelin, Yu. A. Morozov, and M. G. Leonov, Dokl. Earth Sci. 479 (2), 499-502
(2018). https://doi.org/10.1134/S1028334X18040165

11. A. K. Rybin, V. Y. Batalev, E. A. Bataleva, V. D. Bragin, G. G. Schelochkov, M. G. Leonov, E. S. Przhiyalgovskii, and Y. A. Morozov, Dokl. Earth Sci. 470 (1), 968971 (2016).

12. E. S. Przhiyalgovskii, E. V. Lavrushina, M. G. Leonov, V. Y. Batalev, E. A. Bataleva, and A. K. Rybin, Russ. Geol. Geophys. 59 (4), 335-350 (2018). https://doi.org/10.1016/j.rgg.2017.09.003

13. E. A. Bataleva, V. Yu. Batalev, V. E. Matyukov, A. K. Rybin, E. S. Przhiyalgovskii, E. V. Lavrushina, and M. G. Leonov, Dokl. Earth Sci. 475 (2), 930-934 (2017). https://doi.org/10.1134/S1028334X1708013X

14. M. N. Berdichevsky and V. I. Dmitriev, Models and Methods of Magnetotellurics (Springer-Verlag, Berlin, 2008).

15. W. L. Rodi and R. L. Mackie, Geophysics 66, 174-187 (2001).

16. Yu. A. Morozov, A. I. Smul'skaya, A. L. Kulakovskiy, and M. A. Matveev, Izv., Phys. Solid Earth 54 (1), 121 (2018).

17. E. A. Bataleva, V. Yu. Batalev, and A. K. Rybin, Litosfera, No. 5, 81-89 (2015).

18. A. K. Rybin, Deep Structure and Recent Geodynamics of the Central Tien Shan by Magnetotellurgic Research Results (Nauchn. Mir, Moscow, 2011) [in Russian].

19. M. G. Leonov, Yu. A. Morozov, Yu. P. Stefanov, and R. A. Bakeev, Geodyn. Tectonophys. 9 (3), 693-720 (2018). https://doi.org/10.5800/GT-2018-9-3-0368

20. M. G. Leonov, Yu. A. Morozov, E. S. Przhiyalgovskii, A. K. Rybin, R. A. Bakeev, E. V. Lavrushina, and Yu. P. Stefanov, Geotectonics 54 (2), 147-173 (2020).

Translated by A. Bobrov 